\title{
Transaxillary gasless endoscopic thyroidectomy versus conventional open thyroidectomy: systematic review and meta-analysis
}

\author{
Kristijonas Jasaitis ${ }^{1}$, Anna Midlenko ${ }^{2}$, Aigerim Bekenova ${ }^{2}$, Povilas Ignatavicius ${ }^{3}$, Antanas Gulbinas ${ }^{2}$, Albertas Dauksa $^{1}$ \\ ${ }^{1}$ Department of Surgery, Lithuanian University of Health Sciences, Kaunas, Lithuania \\ ${ }^{2}$ Department of Medicine, School of Medicine, Nazarbayev University, Nur-Sultan, Kazakhstan \\ ${ }^{3}$ Klinik für Viszeral- und Transplantationschirurgie, Universitätsspital Zürich, Zürich, Switzerland
}

Videosurgery Miniinv 2021; 16 (3): 482-490

DOI: https://doi.org/10.5114/wiitm.2021.105722

\begin{abstract}
Aim: This systematic review and meta-analysis evaluates surgical outcome and safety results of conventional (OT) versus endoscopic transaxillary gasless thyroidectomies (ET).

Material and methods: A systematic literature search was performed. The weighted mean differences or the odd ratios with corresponding $95 \% \mathrm{Cls}$ were examined for surgical outcomes and complications. The results were analysed using fixed-or random-effects models. The heterogeneity was checked by the Cochran $Q$ test and the extent of inconsistency was evaluated by the $I^{2}$ statistic.

Results: Ten studies and 1597 patients were included. All studies found that ET required longer operative time. Postoperative pain was significantly lower after ET on day 1 and day 7. No statistical difference was found in complication rates.

Conclusions: ET has disadvantages such as longer surgery time, but it is a feasible and safe procedure with lower postoperative pain and comparable complication rates to OT. However, good quality prospective randomised studies are necessary to draw firmer conclusions.
\end{abstract}

Key words: thyroidectomy, meta-analysis, conventional, endoscopic, transaxillary, gasless.

\section{Introduction}

Conventional open thyroidectomy (OT) is considered as a gold standard and is widely practiced all over the world. However, since there are a significant percentage of young female people who need this surgery, many ask for alternative surgical methods to deliver better cosmetic results. Endoscopic thyroidectomy (ET) has emerged as an alternative to conventional trans-cervical thyroidectomies; it was developed to minimise post- operative morbidity and avoid neck scarring, thus improving postoperative quality of life [1]. Gasless ET includes the anterior chest approach, transoral, axillary, postauricular, and facelift approaches. The methods with $\mathrm{CO}_{2}$ insufflation include the cervical approach, axillary, anterior chest, breast, transoral, and various axillo-breast approaches [2-5]. Some researchers suggest that ET leads to fewer postoperative infections [6] and less bleeding [6, 7]. Conversely, gas-dependent techniques may lead to subcutaneous and mediastinal emphysema and in

Address for correspondence

Kristijonas Jasaitis, Department of Surgery, Lithuanian University of Health Sciences, Kaunas, Lithuania, e-mail: kristijonas.jasaitis@lsmu.It 
some cases to pneumothorax and cardiac arrhythmia $[8,9]$.

The endoscopic technique is more difficult to perform; it is very much surgeon-dependent $[1,10]$ and is more expensive than the traditional approach [11] but at the same time cheaper than robot-assisted methods [12]. Among the other techniques, gasless transaxillary thyroidectomy has been widely used for the last several years [13]. In this technique, dissection of the anterior surface of the sternocleidomastoid muscle and strap muscle can be avoided to prevent postoperative hypoesthesia of the anterior neck [14]. The oncologic safety of gasless transaxillary thyroidectomy has been demonstrated by several authors $[14,15]$.

In recent years, several institutions have conducted studies to assess the effectiveness and surgical outcomes of OT and ET. One meta-analysis was conducted between ET and OT, but it was focused on patients with papillary thyroid microcarcinoma (PTMC) [16]. Another meta-analysis was published in 2018 and was conducted between OT and ET, including the bilateral axillo-breast approach (BABA), bilateral breast approach (BBA), unilateral axillo-breast approach (UABA), and transaxillary approach (TAA); only patients with papillary thyroid cancer (PTC) were included in the analysis [17].

\section{Aim}

Despite the growing number of publications, a comparison of gasless transaxillary thyroidectomy with conventional open thyroidectomy has not been reported yet. In this study, we aimed to compare the surgical outcomes of these two approaches, where the pooled rate of complications was determined as the primary outcome.

\section{Material and methods}

This meta-analysis was conducted in accordance with the PRISMA statement [18]. The study was prospectively registered with the PROSPERO database (Registration CRD42020169718).

\section{Search strategy}

A systematic search was conducted using the PubMed, Embase, Medline, and Cochrane Library electronic databases on 20 February 2020. We used the following keywords and Medical Subject Head- ings (MeSH) terms: 'endoscopy' or 'minimally invasive surgery' or 'axillary endoscopic' and 'thyroidectomy' and 'hemi thyroidectomy' and 'conventional thyroidectomy'.

\section{Study selection}

Two independent authors reviewed study titles and abstracts to exclude irrelevant articles, and studies meeting the inclusion criteria were selected for full-text assessment. The inclusion criteria were as follows: 1) human studies 2) English language; 3) comparative studies between ET and OT; and 4) studies comparing no less than one outcome of surgery. The exclusion criteria for our study were as follows: 1) studies that were case reports, letters, reviews, conferences, editorials, or expert opinions; 2) studies that focused on robotic or robot-assisted thyroidectomy; and 3) studies that focused on gas-dependent endoscopic approaches.

\section{Data extraction and quality assessment}

All data were extracted into standardised forms by 2 independent reviewers. The primary data were extracted from each study and included the first author, year of publication, geographical region, study type, number of patients, patient demographics, pathological characteristics, extent of thyroidectomy, overall outcome, and complication rate. Outcomes included operative time and hospitalisation period. Complications included post-operative bleeding, hypoparathyroidism, recurrent laryngeal nerve (RLN) palsy and seroma formation, and the level of postoperative pain. The quality assessment of non-randomised studies was performed by two independent reviewers using the Newcastle-Ottawa Scale.

\section{Statistical analysis}

Review Manager Software version 5.3 (The Nordic Cochrane Centre, The Cochrane Collaboration, Copenhagen, 2014) was used for data analysis. For continuous outcomes, the weighted mean differences (WMDs) with corresponding 95\% Cls were calculated. For dichotomous outcomes, ORs with corresponding $95 \% \mathrm{Cls}$ were examined. The results were analysed using fixed- or random-effects models. The statistical heterogeneity was assessed by the Cochrane $Q$ test and the extent of inconsistency was evaluated by the $I^{2}$ statistic, which was divided into 3 degrees including low (25-49\%), moderate 


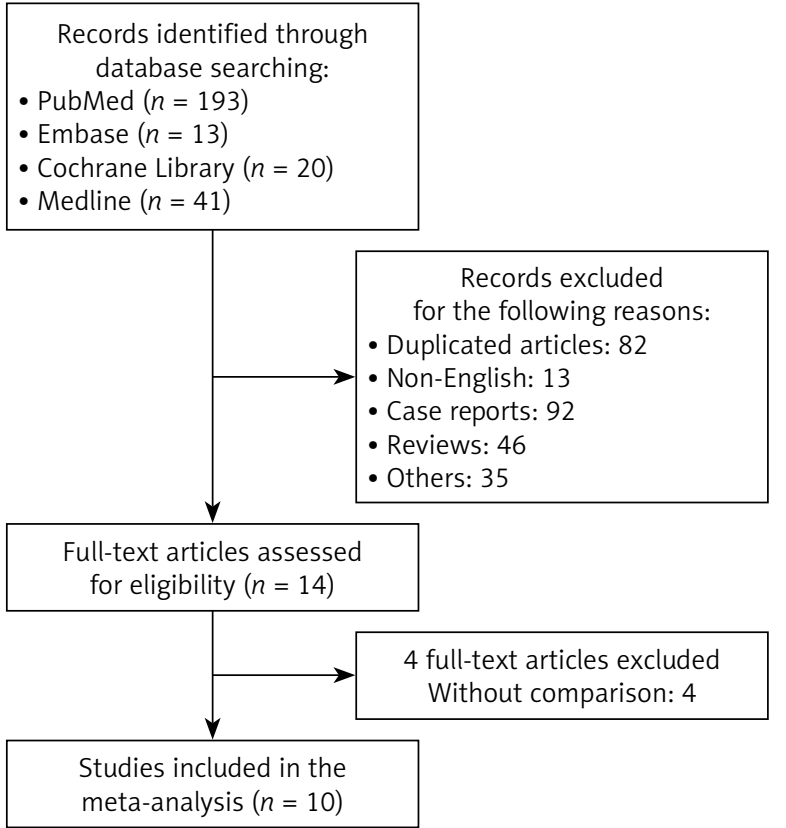

Figure 1. Flow diagram for the search strategy and study selection

(50-74\%), and high ( $\geq 75 \%$ ) levels. When $p>0.1$ and $1^{2}<50 \%$, a fixed-effects model was used; otherwise, a random-effects model was applied.

\section{Results}

Our initial search showed 267 potentially relevant articles. Fourteen potential articles were identified after screening titles and abstracts. After a fulltext review, an additional 4 studies did not show a comparative group and were excluded from the analysis [19-22]. Finally, 10 observational articles were obtained for final analysis (Figure 1).

The quality assessment of the included studies was performed according to the Newcastle-Ottawa Scale (NOS). The quality was assessed based on 3 aspects: patient selection, comparability of groups, and outcome assessment. Evaluation ranged from 0 to 9 points and studies with NOS score of $\geq 6$ were considered as high quality.

In this meta-analysis we included 10 studies and 1597 patients. Among these there were 7 retrospective and 3 prospective studies; the majority of them were conducted in the Republic of Korea (60\%). NOS scores ranged from 5 to 9 , with the majority of the included studies being of high quality (NOS scores $\geq 6$ ). However, it should be emphasised that studies included in the meta-analysis describe early experiences in the gasless transaxillary approach.
The inclusion criteria were benign lesions less than $5 \mathrm{~cm}$ and malignant thyroid tumour less than $1 \mathrm{~cm}$ in diameter. Patients with tumour less than $1 \mathrm{~cm}$ in diameter in both OT and ET groups were present in 4 studies $[6,7,23,24]$.

In all studies, patients with thyroiditis, signs of malignant local invasion on preoperative ultrasonography, previous neck surgery and neck irradiation, Graves' disease, lateral neck node metastasis or distant metastasis that required modified radical neck dissection, and anaplastic or medullary thyroid carcinoma were excluded from the analysis.

In one study [11], BMI > $30 \mathrm{~kg} / \mathrm{m}^{2}$, thickness of the skin, and subcutaneous tissue of the neck and chest $>2 \mathrm{~cm}$ were also criteria for exclusion from the analysis. Patients with lesions located in the thyroid dorsal area or adjacent to the tracheoesophageal groove were excluded from the study by Park et al. [25]. Detailed information of included studies is shown in Table I.

We analysed the overall complication rate as the primary outcome. Six $[6,7,11,24-26]$ out of 10 authors presented data on different complications after transaxillary and conventional open thyroidectomy, including postoperative bleeding, vocal cord paralysis, haematoma/seroma formation, hypoparathyroidism, paraesthesia, and infection. There was no significant difference in terms of the number of events in the 2 groups $(\mathrm{OR}=1.11,95 \% \mathrm{Cl}$ : $0.81-1.52, p=0.52$ ). However, low heterogeneity $\left(I^{2}=9 \%, p=0.36\right)$ was observed among the studies (Figure $2 \mathrm{~A}$ ).

In order to evaluate possible publication bias, funnel plot analysis was conducted showing the asymmetrical distribution of the included studies. Risk of publication bias was confirmed by Egger's test. To reduce the heterogeneity among the studies, we performed a subgroup analysis.

Vocal cord paralysis was reported in 6 studies [6, 7, 11, 24-26], with the tendency to fewer paralysis cases with conventional thyroidectomy; however, the difference was not significant $(\mathrm{OR}=1.66,95 \% \mathrm{Cl}$ : $0.98-2.80, p=0.06)$ and no heterogeneity $\left(I^{2}=0 \%\right)$ was detected (Figure $2 \mathrm{~B}$ ).

Two studies [7, 24] compared the presence of hypoparathyroidism. There was a tendency of fewer cases of transient and permanent hypocalcaemia in the endoscopic thyroidectomy group $(\mathrm{OR}=0.89$, $95 \% \mathrm{Cl}: 0.53-1.50, p=0.67)$, and this result was associated with significant heterogeneity between 


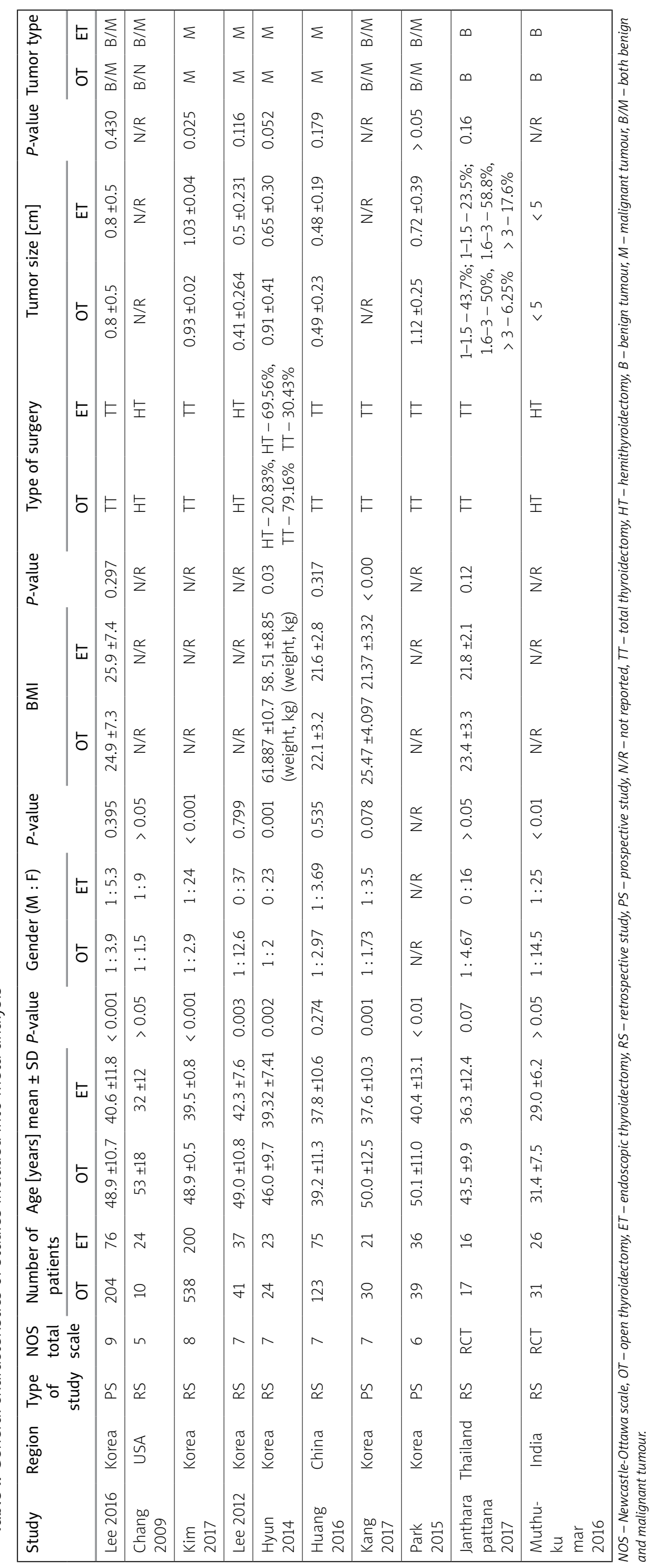


A

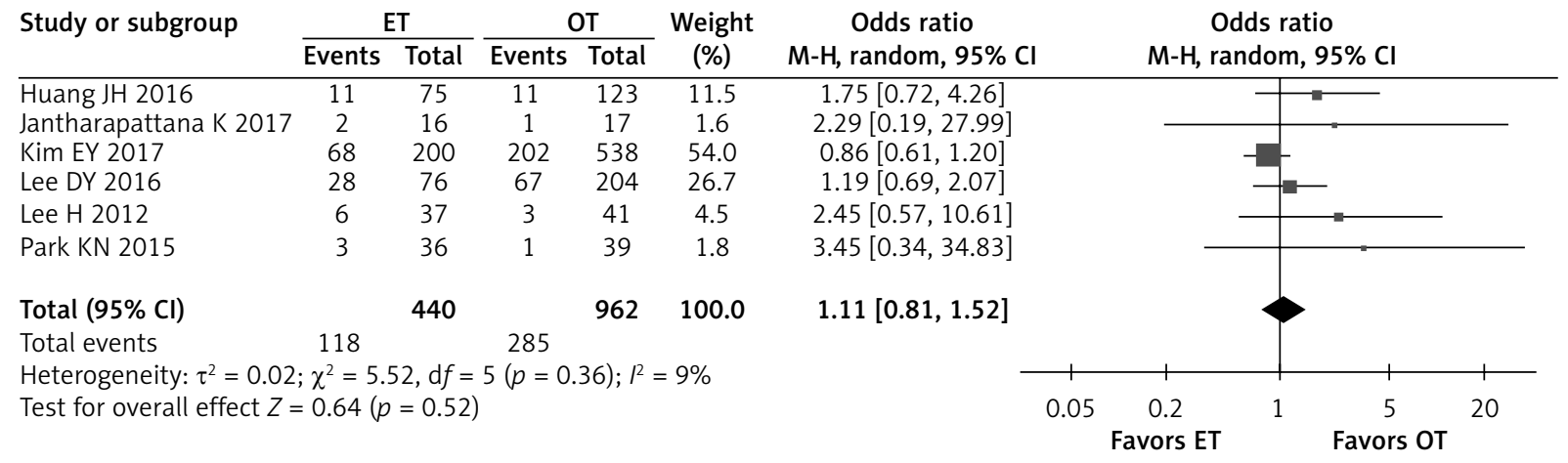

B

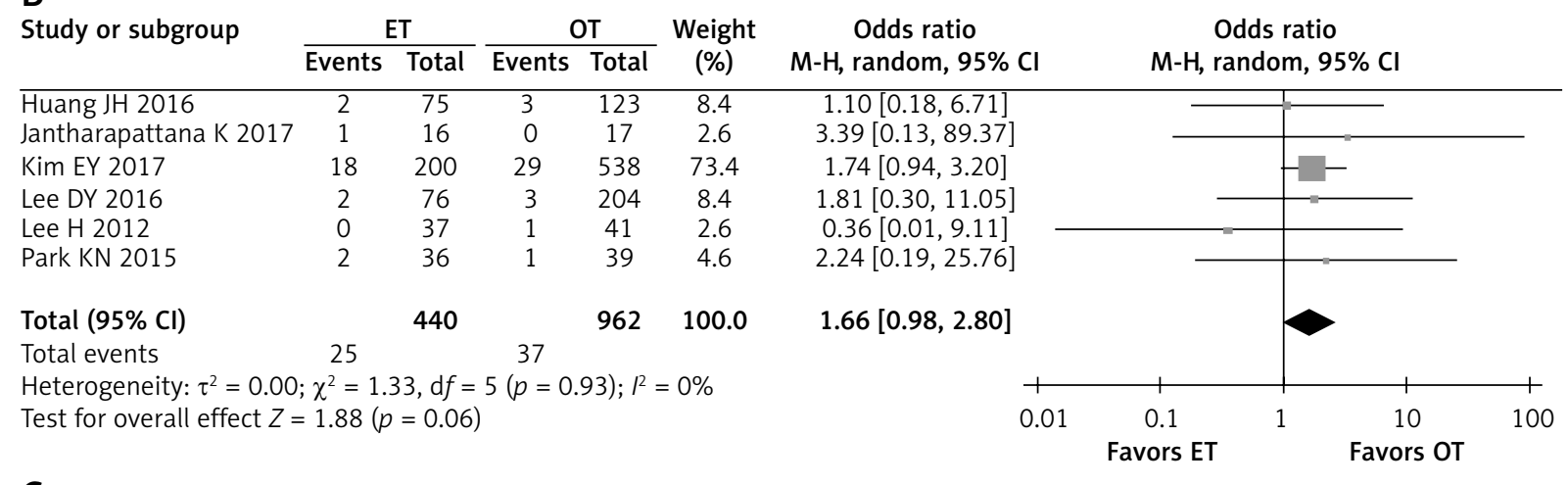

C

\begin{tabular}{|c|c|c|c|c|c|}
\hline \multirow[t]{2}{*}{ Study or subgroup } & \multicolumn{2}{|c|}{ ET } & \multicolumn{2}{|c|}{ От } & \multirow{2}{*}{$\begin{array}{l}\text { Weight } \\
(\%)\end{array}$} \\
\hline & Events & Total & Events & Total & \\
\hline Kim EY 2017 & 48 & 200 & 165 & 538 & 58.0 \\
\hline Lee DY 2016 & 26 & 76 & 61 & 204 & 42.0 \\
\hline Total $(95 \% \mathrm{Cl})$ & \multirow{2}{*}{\multicolumn{5}{|c|}{$\begin{array}{lllll} & 276 & & 742 & 100.0 \\
74 & & 226 & & \end{array}$}} \\
\hline & & & & & \\
\hline $\begin{array}{l}\text { Heterogeneity: } \tau^{2} \\
\text { Test for overall ef }\end{array}$ & $\chi^{2}=2$ & 43, d $=$ & $1(p=$ & 12). $12^{2}=-(-1$ & $=59 \%$ \\
\hline
\end{tabular}

Odds ratio $\mathrm{M}-\mathrm{H}$, random, $95 \% \mathrm{Cl} \quad \mathrm{M}-\mathrm{H}$, random, $95 \% \mathrm{Cl}$

$0.71[0.49,1.04]$

$1.22[0.70,2.14]$

$0.89[0.53,1.50]$

Test for overall effect: $Z=0.42(p=0.67)$

D

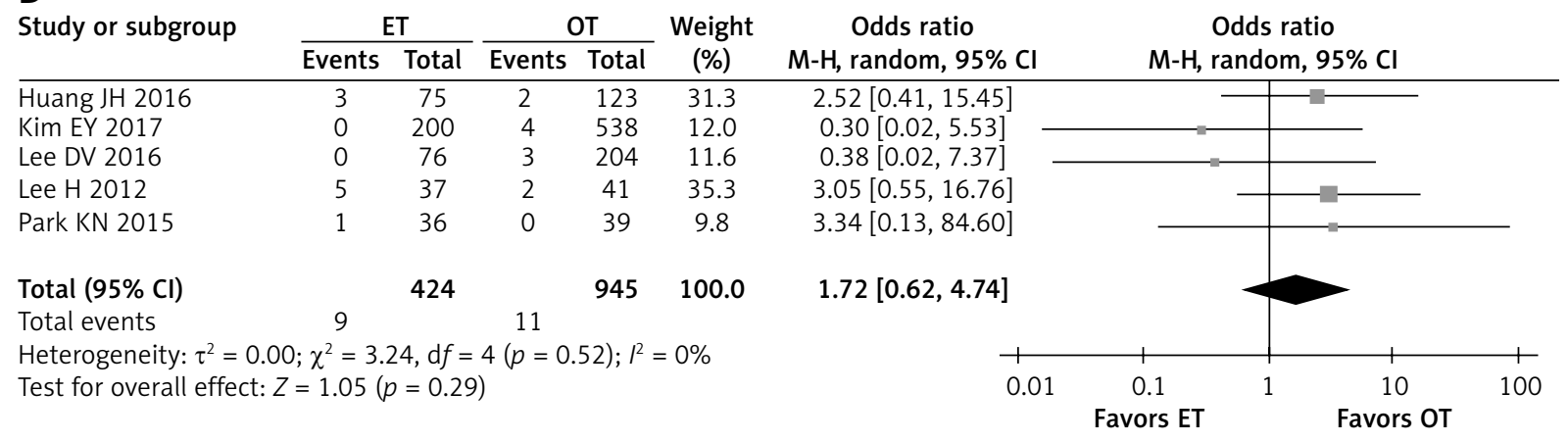

Figure 2. Meta-analysis of overall complication events (A), vocal cord paralysis (B), hypoparathyroidism (C), postoperative bleeding (D) 
E

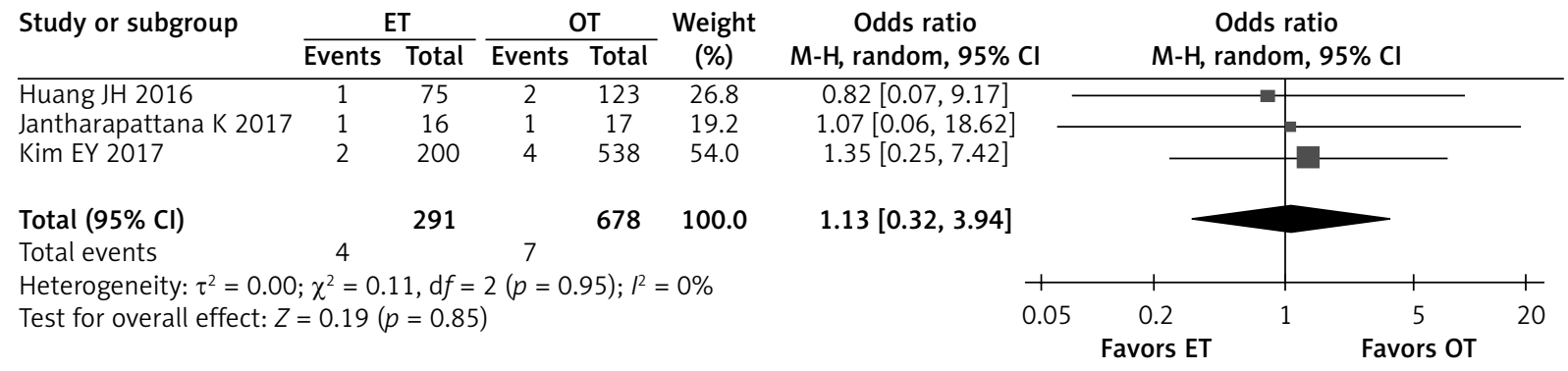

$\mathrm{F}$

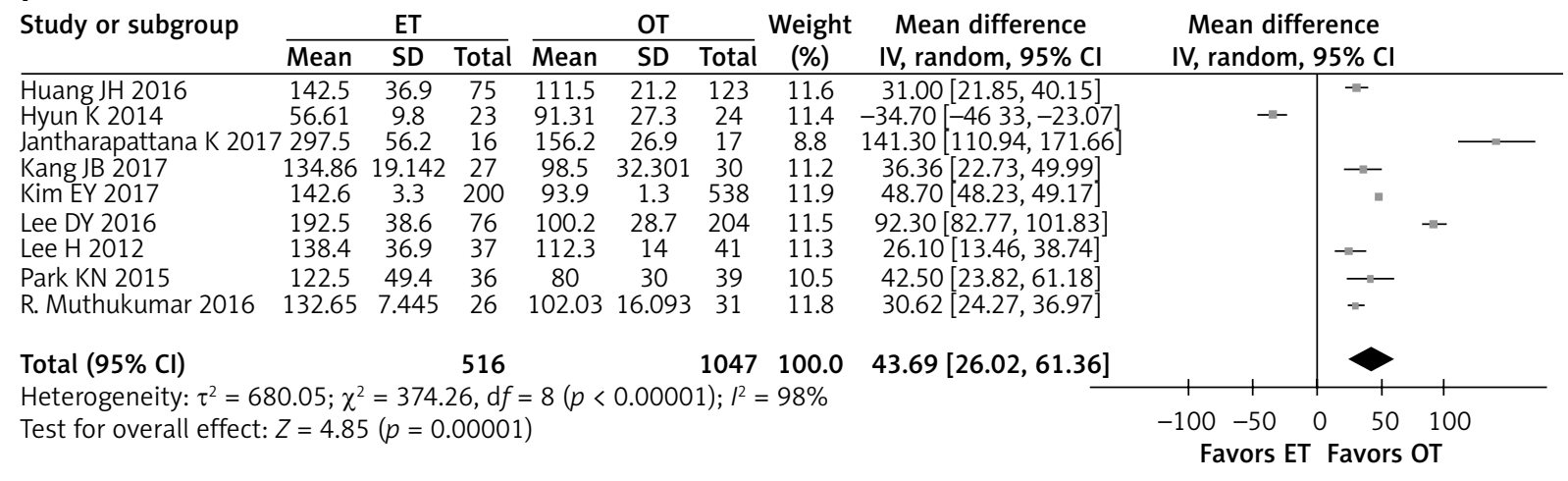

G

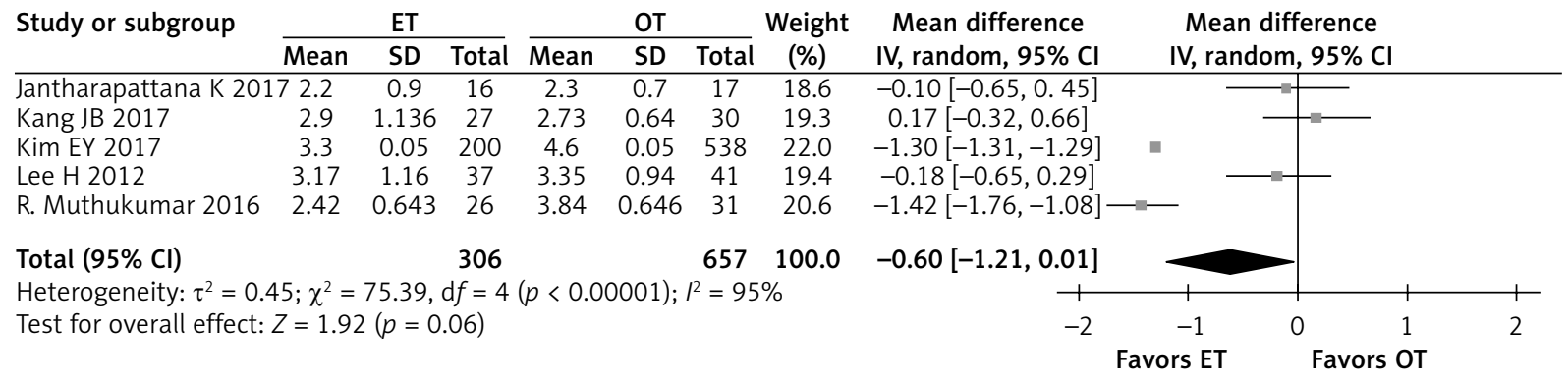

$\mathrm{H}$

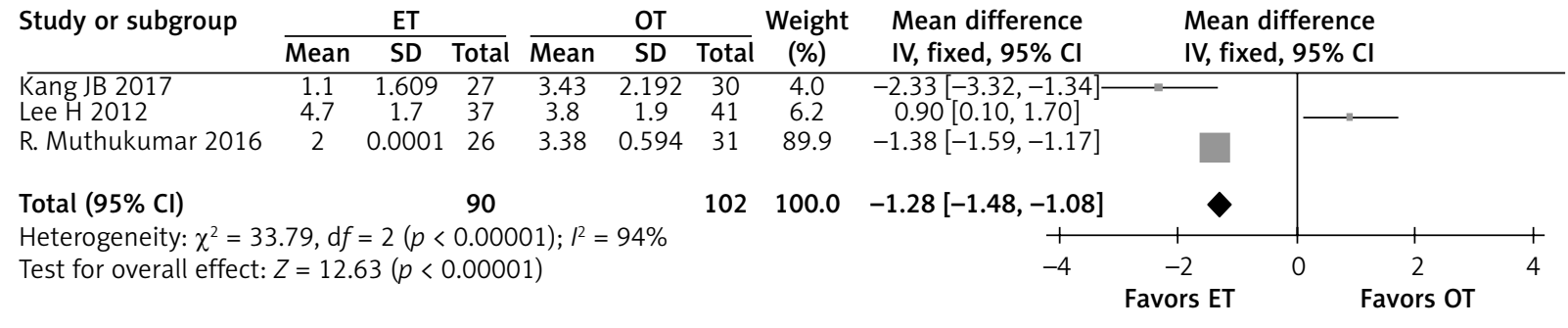

I

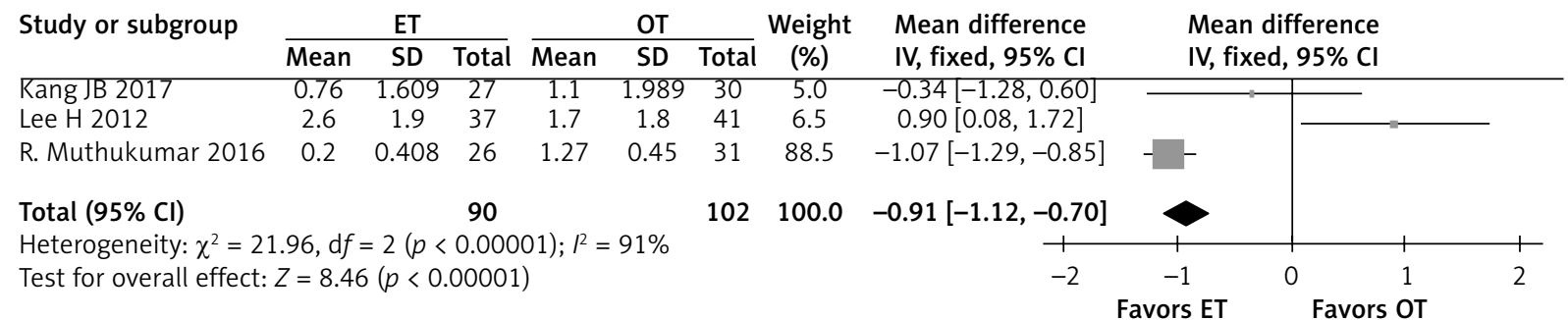

Figure 2. Cont. Seroma formation (E), operation time (minutes) (F), hospital stay (days) (G), postoperative pain, day 1 (VAS) (H), postoperative pain, day 7 (VAS) (I) 
the 2 studies $\left(R^{2}=99 \%, p=0.12\right)$ (Figure $2 \mathrm{C}$ ). Regarding postoperative bleeding $(\mathrm{OR}=1.72,95 \% \mathrm{Cl}$ : 0.62-4.74, $p=0.29$ ) and postoperative seroma formation (OR $=1.13,95 \% \mathrm{Cl}: 0.32-3.94, p=0.85)$, no heterogeneity existed among the studies and no significant differences between groups were observed (Figures 2 D, E).

All studies showed that endoscopic thyroidectomy took significantly more time than conventional thyroidectomy $(\mathrm{WMD}=43.69,95 \% \mathrm{Cl}: 26.02-61.36$, $p<0.00001)$. However, there was a high level of heterogeneity among studies $\left(R^{2}=98 \%, p<0.00001\right)$ (Figure $2 \mathrm{~F}$ ).

Hospital stay was assessed in 6 studies $[9,11$, $21,22,24,25]$. Longer hospitalisation was found after conventional thyroidectomy (WMD $=-0.60$, 95\% Cl: -1.21 to $0.01, p=0.06$ ) (Figure $2 \mathrm{G}$ ).

Postoperative pain on day 1 and day 7 was assessed in 3 studies [13, 26, 27] using a visual analogue scale (VAS). The results showed that postoperative pain on both day 1 (WMD $=-1.28$, $95 \% \mathrm{Cl}:-1.48$ to $-1.08, \mathrm{p}<0.00001)$ and day 7 (WMD $=-0.91,95 \% \mathrm{Cl}:-1.12$ to $-0.70, p<0.00001)$ was significantly higher in the open thyroidectomy group compared with the endoscopic thyroidectomy group. However, there was a high heterogeneity between both studies with $l^{2}=94 \%, p<0.00001$ and $l^{2}$ $=91 \%, p<0.0001$, respectively (Figures $2 \mathrm{H}, \mathrm{I}$ ).

\section{Discussion}

Conventional open thyroidectomy is advocated as the gold standard and is widely practiced for the treatment of thyroid diseases, but it leaves a scar on the anterior neck that leads to a low patient satisfaction rate. In modern society, more and more patients ask for better cosmetic results. Therefore, endoscopic thyroidectomy is considered as an alternative way to minimise postoperative morbidity and avoid neck scarring. Endoscopic neck surgery was first introduced in 1996, and Huscher performed the first endoscopic thyroidectomy in 1997 [28]. Several studies have been published in recent years to compare the efficacy of endoscopic thyroidectomy versus conventional open thyroidectomy. There are studies that have investigated the effectiveness of total endoscopic thyroidectomy compared with conventional open thyroidectomy in patients with papillary thyroid cancer [17] and papillary microcarcinoma [16]. Other studies compared cosmetic results
[6], swallowing disorders [23], and postoperative pain $[13,29]$ following conventional and endoscopic thyroidectomies. Despite the available publications on this topic, there has been no systemic data analysis answering the question of whether gasless endoscopic thyroidectomy is as safe as conventional thyroidectomy.

The objectives of any endoscopic technique are better cosmetic results, less pain, lower morbidity, and better patient satisfaction. Therefore, we conducted a meta-analysis to compare the safety of gasless transaxillary thyroidectomy versus conventional open thyroidectomy in patients with benign and malignant thyroid tumours (microcarcinomas).

In the present meta-analysis, we considered safety as a primary outcome and compared conventional and transaxillary thyroidectomies in terms of the overall rate of complications such as postoperative bleeding, vocal cord paralysis, haematoma/seroma formation, hypoparathyroidism, paraesthesia, and infection. We found no significant difference in the overall complication rates between the 2 groups, indicating that transaxillary gasless thyroidectomy is as safe as conventional open thyroidectomy.

It is known that major complications of thyroidectomy include recurrent laryngeal nerve injury, postoperative haemorrhage, and hypocalcaemia [30]. Recurrent laryngeal nerve palsy is considered as one of the major complications of all thyroid surgeries. A meta-analysis has shown a tendency of lower vocal fold paralysis rate after open thyroidectomy in comparison with endoscopic thyroidectomy. However, this result is not consistent with previous publications $[15,29]$ and was most probably associated with the small number of studies and the learning curve.

Transient and permanent hypoparathyroidism also remain the most common complications in thyroid surgery, with an incidence of $7 \%$ to $51 \%$ [30, 31]. In our meta-analysis, cases with transient and permanent hypocalcaemia were merged, and we observed a tendency of fewer cases of hypoparathyroidism in the endoscopic group in comparison with conventional thyroidectomy. This might be due to improved visualisation of the surgical field and better identification of the important structures such as the parathyroid glands [26, 32].

Bleeding is also reported as a major complication in open and endoscopic thyroidectomies. The bleeding rate after open and endoscopic techniques varies from $0.36 \%$ to $4.3 \%$ [33]. Seroma formation subse- 
quent to thyroid surgery varies from $1.3 \%$ to $7 \%$ [34]. The results of our meta-analysis showed no significant differences in postoperative bleeding and seroma formation in transaxillary thyroidectomy versus open thyroidectomy. This means that transaxillary thyroidectomy is as safe as open surgery with regards to postoperative bleeding and seroma formation.

However, the results of our meta-analysis showed that the operative time in the endoscopic approach was approximately 43 min longer than in the conventional thyroidectomy group. This may be attributed to the time needed to create the skin flap [35]. Other studies also showed that endoscopic thyroidectomy takes longer than conventional thyroidectomy because more time is required to create the skin flap and the working space around the thyroid $[36,37]$.

Thyroid surgery is a short-stay procedure, and moderate pain is a major component of postoperative quality of care. In our meta-analysis, we evaluated the overall hospital stay at the time of the surgery and merged the preoperative and postoperative days that patients spent in the hospital. It was revealed that patients in the endoscopic thyroidectomy group had a slightly shorter hospital stay, which can be explained by the significant reduction in postoperative pain in that group of patients as compared to the open thyroidectomy group.

Kang et al. showed that there was no difference in postoperative pain between open and gasless transaxillary thyroidectomy [13]. However, our results demonstrate that postoperative pain was significantly lower on day 1 and day 7 in the endoscopic thyroidectomy group compared with the open thyroidectomy group. The reasons for less pain in the transaxillary group might be associated with the different incision site (axilla versus anterior neck) and different nerve distribution according to the anatomical site $[29,38]$. Also, incision site movement is different during the postoperative period. Patients who undergo transaxillary thyroidectomy usually have fewer movements around the incision site (axilla), but patients who undergo conventional thyroidectomy must frequently move the area corresponding to the incision site (neck), which might increase postoperative pain [29].

\section{Conclusions}

This meta-analysis suggests that gasless transaxillary thyroidectomy is feasible and as safe as open thyroidectomy with regards to the complication rate. Despite the longer operation time, a shorter hospital stay and better patient satisfaction rate with regards to pain and cosmetic results were observed. However, publications of moderate level of quality according to NOS were analysed. Good quality prospective randomised studies are necessary to draw firmer conclusions.

\section{Conflict of interest}

The authors declare no conflict of interest.

\section{References}

1. Tae K, Ji YB, Song CM, Ryu J. Robotic and endoscopic thyroid surgery: evolution and advances. Clin Exp Otorhinolaryngol 2019; 12: 1-11.

2. Chung EJ, Park MW, Cho JG, et al. A prospective 1-year comparative study of endoscopic thyroidectomy via a retroauricular approach versus conventional open thyroidectomy at a single institution. Ann Surg Oncol 2015; 22: 3014-21.

3. Sung ES, Ji YB, Song CM, et al. Robotic thyroidectomy: comparison of a postauricular facelift approach with a gasless unilateral axillary approach. Otolaryngol Head Neck Surg 2016; 154: 997-1004.

4. Xu Z, Meng Y, Song J, et al. The role of carbon nanoparticles in guiding central neck dissection and protecting the parathyroid in transoral vestibular endoscopic thyroidectomy for thyroid cancer. Videosurgery Miniinv 2020; 15: 455-61.

5. Xu Z, Song J, Wang Y, et al. A comparison of transoral vestibular and bilateral areolar endoscopic thyroidectomy approaches for unilateral papillary thyroid microcarcinomas. Videosurgery Miniinv 2019; 14: 501-8.

6. Huang JK, Ma L, Song WH, et al. Quality of life and cosmetic result of single-port access endoscopic thyroidectomy via axillary approach in patients with papillary thyroid carcinoma. Onco Targets Ther 2016; 9: 4053-9.

7. Lee DY, Lim S, Kang SH, et al. A prospective 1-year comparative study of transaxillary total thyroidectomy regarding functional outcomes: is it really promising? Surg Endosc 2016; 30: 1599606.

8. Bhargav P, Kumbhar U, Satyam G, Gayathri K. Gasless single incision trans-axillary thyroidectomy: the feasibility and safety of a hypo-morbid endoscopic thyroidectomy technique. J Minim Access Surg 2013; 9: 116-21.

9. Lee WK, Choi YS, Chae YK, et al. Massive subcutaneous emphysema and hypercarbia during endoscopic thyroidectomy: a case report. Korean J Anesthesiol 2004; 47: 898-901.

10. Lin S, Chen ZH, Jiang HG, Yu JR. Robotic thyroidectomy versus endoscopic thyroidectomy: a meta-analysis. World J Surg Oncol 2012; 10: 239.

11. Jantharapattana K, Maethasith J. Transaxillary gasless endoscopic thyroidectomy versus conventional open thyroidectomy: a randomized study. Eur Arch Otorhinolaryngol 2017; 274: 495-500. 
12. Yoo H, Chae BJ, Park HS, et al. Comparison of surgical outcomes between endoscopic and robotic thyroidectomy. J Surg Oncol 2012; 105: 705-8.

13. Kang JB, Kim EY, Park YL, et al. A comparison of postoperative pain after conventional open thyroidectomy and single-incision, gasless, endoscopic transaxillary thyroidectomy: a single institute prospective study. Ann Surg Treat Res 2017; 92: 9-14.

14. Kang SW, Jeong JJ, Yun JS, et al. Gasless endoscopic thyroidectomy using trans-axillary approach; surgical outcome of 581 patients. Endocr J 2009; 56: 361-9.

15. Ikeda Y, Takami H, Sasaki Y, et al. Clinical benefits in endoscopic thyroidectomy by the axillary approach. J Am Coll Surg 2003; 196: 189-95.

16. Wang Y, Liu K, Xiong J, Zhu J. Total endoscopic versus conventional open thyroidectomy for papillary thyroid microcarcinoma. J Craniofac Surg 2015; 26: 464-8.

17. Chen C, Huang S, Huang A, et al. Total endoscopic thyroidectomy versus conventional open thyroidectomy in thyroid cancer: a systematic review and meta-analysis. Ther Clin Risk Manag 2018; 14: 2349-61.

18. Moher D, Liberati A, Tetzlaff J, et al. Preferred reporting items for systematic reviews and meta-analyses: the PRISMA statement. PLoS Medicine 2009; 6: e1000097.

19. Duncan TD, Rashid Q, Speights F, Ejeh I. Endoscopic transaxillary approach to the thyroid gland: our early experience. Surg Endosc 2007; 21: 2166-71.

20. Fan Y, Wu SD, Kong J. Single-port access transaxillary totally endoscopic thyroidectomy: a new approach for minimally invasive thyroid operation. J Laparoendosc Adv Surg Tech A 2011; 21: 243-7.

21. Darail NA, Lee SH, Kang SW, et al. Gasless transaxillary endoscopic thyroidectomy: a decade on. Surg Laparosc Endosc Percutan Tech 2014;24: e211-5.

22. Rao RS, Duncan TD. Endoscopic total thyroidectomy. J Soc Laparoendosc Surg 2009; 13: 522-7.

23. Hyun K, Byon W, Park HJ, et al. Comparison of swallowing disorder following gasless transaxillary endoscopic thyroidectomy versus conventional open thyroidectomy. Surg Endosc 2014; 28: 1914-20.

24. Kim EY, Lee KH, Park YL, et al. Single-incision, gasless, endoscopic trans-axillary total thyroidectomy: a feasible and oncologic safe surgery in patients with papillary thyroid carcinoma. J Laparoendosc Adv Surg Tech 2017; 27: 1158-64.

25. Park KN, Mok JO, Chung CH, Lee SW. Does postthyroidectomy syndrome really exist following thyroidectomy? Prospective comparative analysis of open vs. endoscopic thyroidectomy. Clin Exp Otorhinolaryngol 2015; 8: 76-80.

26. Lee H, Lee J, Sung KY. Comparative study comparing endoscopic thyroidectomy using the axillary approach and open thyroidectomy for papillary thyroid microcarcinoma. World J Surg Oncol 2012; 10: 269.

27. Muthukumar R, Prathap A, Ibrahim M. Transaxillary endoscopic hemithyroidectomy versus open hemithyroidectomy for solitary thyroid nodule: a randomized study. Int J Sci Stud 2016; 4: 79-82.

28. Hüscher CS, Chiodini S, Napolitano C, Recher A. Endoscopic right thyroid lobectomy. Surg Endosc 1997; 11: 877.
29. Ryu HR, Lee J, Park JH, et al. A comparison of postoperative pain after conventional open thyroidectomy and transaxillary single-incision robotic thyroidectomy: a prospective study. Ann Surg Oncol 2013; 20: 2279-84.

30. Bai B, Chen Z, Chen W. Risk factors and outcomes of incidental parathyroidectomy in thyroidectomy: a systematic review and meta-analysis. PLoS One 2018; 13: e0207088.

31. Burger F, Fritsch H, Zwierzina M, et al. Postoperative hypoparathyroidism in thyroid surgery: anatomic-surgical mapping of the parathyroids and implications for thyroid surgery. Sci Rep 2019; 9: 15700.

32. Aïdan P, Bechara M. Gasless trans-axillary robotic thyroidectomy: the introduction and principle. Gland Surgery 2017; 6: 229-35.

33. Pontin A, Pino A, Caruso E, et al. Postoperative bleeding after thyroid surgery: care instructions. SiSli Etfal Hastan Tip Bul 2019; 53: 329-36.

34. Ramouz A, Rasihashemi SZ, Daghigh F, et al. Predisposing factors for seroma formation in patients undergoing thyroidectomy: cross-sectional study. Ann Med Surg 2017; 23: 8-12.

35. Tan Z, Gu J, Han Q, et al. Comparison of conventional open thyroidectomy and endoscopic thyroidectomy via breast approach for papillary thyroid carcinoma. Int J Endocrinol 2015; 2015: 239610.

36. Kim SK, Kang SY, Youn HJ, Jung SH. Comparison of conventional thyroidectomy and endoscopic thyroidectomy via axillo-bilateral breast approach in papillary thyroid carcinoma patients. Surg Endosc 2016; 30: 3419-25.

37. Xiang D, Xie L, Li Z, et al. Endoscopic thyroidectomy along with bilateral central neck dissection (ETBC) increases the risk of transient hypoparathyroidism for patients with thyroid carcinoma. Endocrine 2016; 53: 747-53.

38. Rolke R, Baron R, Maier C, et al. Quantitative sensory testing in the German Research Network on Neuropathic Pain (DFNS): standardized protocol and reference values. Pain 2006; 123 : 231-43.

Received: 25.11.2020, accepted: 18.01.2021. 